Obere Extremität 2020 $15: 295-300$ https://doi.org/10.1007/s11678-020-00609-6 Received: 2 September 2020

Accepted: 1 October 2020

Published online: 28 October 2020

(c) The Author(s) 2020

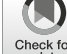

Jana Willin • Jonas Schmalzl · Lars Lehmann · Christian Gerhardt

Klinik für Unfall- und Handchirurgie, ViDia Kliniken Karlsruhe, Karlsruhe, Germany

\title{
Elbow stability after simple elbow dislocation
}

\section{Preliminary results following nonoperative vs. surgical ligamentous repair}

three stages, ranging from a ligament tear (stage 1) to a grossly unstable elbow (stage 3c).

The other postulated theory is based on a valgus force with hyperextension of the elbow [23]. The hyperextension of the elbow with disruption of the medial collateral ligament leads to a dissociation of the coronoid process from the laterally sloping surface of the medial part of the trochlea. This leverage converts the forces to a combination of lateral rotation and valgus strain allowing the radial head to move posteriorly leading to a posterolateral dislocation of the elbow.

A simple dislocation was defined by Josefsson et al. as dislocation without relevant accompanying fractures or bony injuries and minimal periarticular avulsions smaller than 2-3 mm [10]. Therefore, by definition the osseous stability is not compromised in simple dislocation. Still, due to the wide-ranging appearance with a large distribution of soft tissue damage, the term "simple" can lead to underestimating the injury. To call these dislocations "ligamentous dislocation" might therefore be more expedient. Besides the ligaments, the common extensors and the flexor/pronator mass have been recognized as import dynamic stabilizers of the elbow $[1,12]$.

After closed reduction of the dislocated elbow joint, a clinical and radiographic evaluation of the joint should be carried out in order to support decisionmaking for further therapy [26]. Since in most cases nonoperative treatment will achieve satisfactory results, short-term immobilization with early functional re- habilitation (i.e., overhead motion protocol) has been established $[9,10,14$, 25].

Nevertheless, some patients show inferior results with persistent pain, instability, restricted movement, and degenerative changes $[2,8,13,15]$. Inadequate ligament as well as muscle/tendon healing and incomplete compensation of the extensor and flexor/pronator mass are often discussed as a possible cause $[8,11]$. Schnetzke et al. demonstrated that patients with a higher grade of instability, defined as a valgus or varus stress angulation of $>10^{\circ}$ on anteroposterior views following closed reduction, had a greater extension deficit and inferior clinical results after nonoperative treatment than patients with a minor instability (stress angulation $<10^{\circ}$; [22]).

The main goal of the present study was to compare the clinical and functional results with clinical and ultrasound-based testing for translation/angulation following nonoperative treatment and ligament repair after ligamentous elbow dislocation. Our hypothesis was that ligament repair will lead to sufficient ligament healing and decreased elbow translation or angulation.

\section{Patients and methods}

A retrospective evaluation was performed, identifying 30 patients who had been treated for ligamentous elbow dislocation at our department between January 2015 and December 2018. The study was approved by the local ethics committee. All patients gave their written 

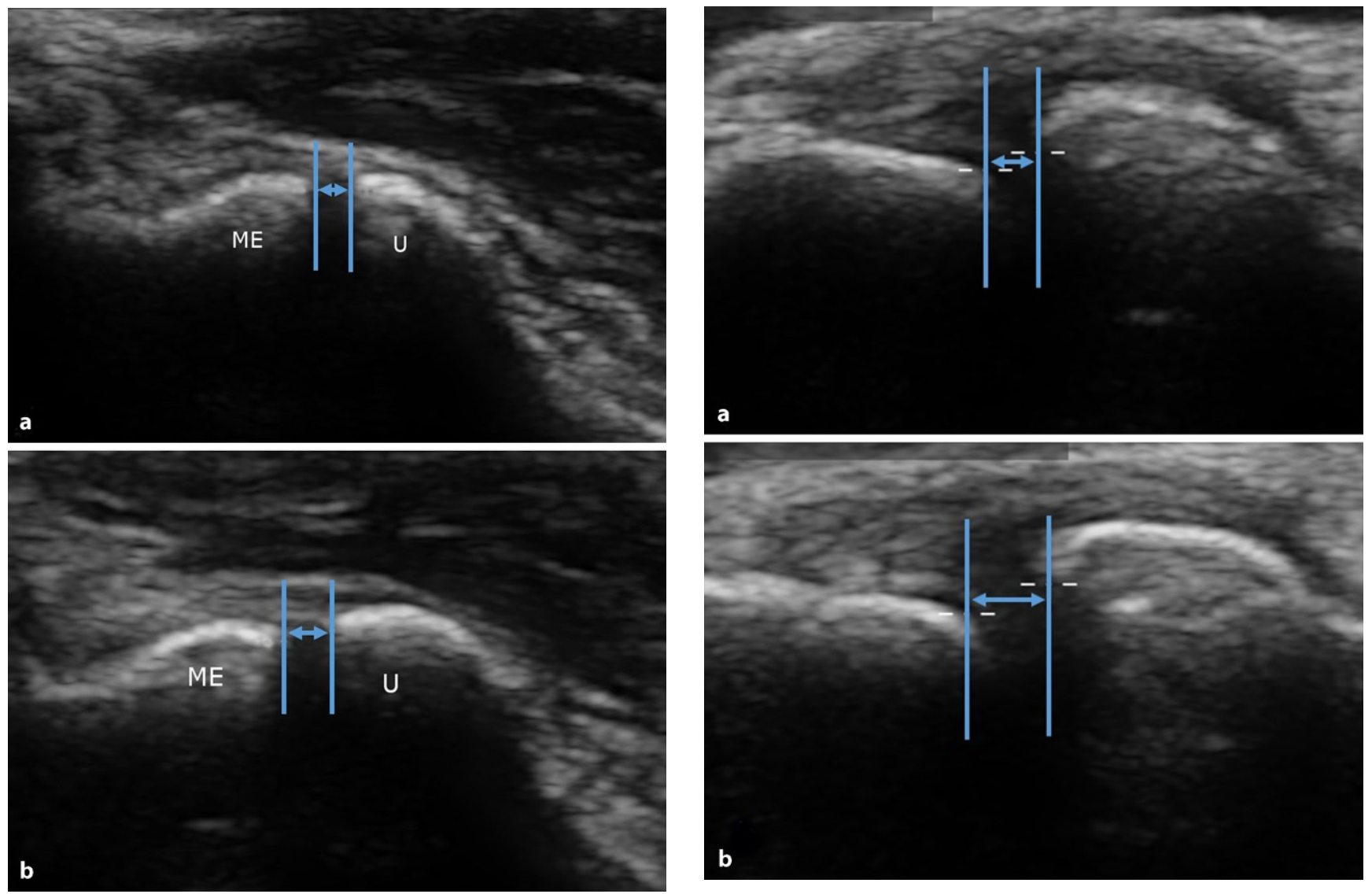

Fig. $1 \Delta$ Sonographic evaluation of the medial elbow: a unstressed, $\mathbf{b}$ with

Fig. $2 \Delta$ Sonographic evaluation of the lateral elbow: a unstressed, $\mathbf{b}$ with valgus stress. ME medial epicondyle of the humerus, $U$ ulna posterolateral rotatory stress

informed consent before being included in the study.

The indication for nonsurgical or surgical therapy was made depending on the degree of instability and the ability to stabilize the elbow joint during follow-up examination allowing for a stable arc of motion up to approximately $30^{\circ}$ of extension. Nine patients were treated nonoperatively (group A), the remaining 21 patients underwent ligamentous repair (group B). Patients under the age of 18 years, with associated fractures or previous trauma, previous surgery, preexisting disease or osteoarthritis as well as patients with dislocations of both elbows were excluded due to the lack of comparability.

In total, 14 of the initial 31 patients were included, nine with surgical repair and five with nonoperative treatment. Eight patients could not be contacted due to incomplete contact information or relocation.

\section{Treatment}

Nonoperative treatment was performed by short-term immobilization in a plaster cast after reduction. After approximately 7-14 days, mobilization in a motion-controlled splint (medi Epico ROMs, medi GmbH \& Co. KG, Bayreuth, Germany) with an extension deficit of $20^{\circ}$ was allowed for a further 5 weeks.

Ligamentous repair was performed depending on the main direction of instability. As a rule, suture anchors were used for the repair of the collateral ligaments and the corresponding muscle/tendon attachments. Two patients underwent repair of only the medial collateral ligaments, while two patients underwent repair of only the lateral collateral ligaments. With the remaining five patients, ligamentous repair was performed on both the medial and lateral collateral ligaments.

\section{Clinical and functional evaluation}

A detailed clinical examination of the elbow and the healthy opposite side was made and specific instability tests were carried out in addition to the range of motion (ROM). Clinical signs of instability were evaluated including medial stability testing with the valgus stress test and the moving valgus stress test [19]. Furthermore, signs of posterolateral rotatory instability (PLRI) were evaluated using the posterolateral rotatory drawer test (PRDT), the posterolateral rotatory apprehension test (PRAT), the tabletop relocation test, the stand-up test, and the push-up test $[3,16,20]$.

Additionally, the Subjective Elbow Value (SEV), the Mayo Elbow Performance Score (MEPS), the Quick DASH Score, the Broberg and Morrey rating scale, and the Oxford Elbow Score (OES) were used for functional evaluation. 
Obere Extremität 2020 · 15:295-300 https://doi.org/10.1007/s11678-020-00609-6

(c) The Author(s) 2020

J. Willin · J. SchmalzI · L. Lehmann · C. Gerhardt

\section{Elbow stability after simple elbow dislocation. Preliminary results following nonoperative vs. surgical ligamentous repair}

Abstract

Aim. We aimed to compare the clinical results after ligamentous elbow dislocation between patients treated nonoperatively (group A) and patients who underwent ligamentous repair (group B).

Methods. Hospital records were investigated for cases of ligamentous elbow dislocation from January 2015 to December 2018. In total, 30 patients were identified: nine with nonoperative treatment and 21 with surgical ligamentous repair. The range of motion (ROM) including arc of extension/flexion and pronation/supination, valgus instability, and posterolateral rotatory instability were evaluated. The scores of several outcome measures assessing elbow injury were evaluated. Sonographic examination was performed on all patients to evaluate translation under valgus and posterolateral rotatory stress.

Results. Overall, 14 patients with simple elbow dislocation (group $A n=5,46.4 \pm 19.3$ years, follow-up [FU] $27 \pm 12.4$ months; group $B$ $n=9,57.3 \pm 21.0$ years, FU $36 \pm 11.1$ months; 4 female patients in each group) were evaluated. No significant difference was seen in extension/flexion and ext/flex-arc although there was a tendency to limited extension $(p=0.07)$ in group A. A significantly reduced supination $\left(84 \pm 15^{\circ}\right.$ vs. $\left.77 \pm 21^{\circ}, p=0.02\right)$ was observed regarding the contralateral side in group B. There was no significant difference in the evaluated scores between the groups. A significantly increased medial angulation during ultrasound evaluation was found in group B compared with the contralateral side. Conclusion. There were no significant differences concerning ROM and functional scores between the nonoperative treatment and ligamentous repair groups. On clinical evaluation, a higher rate of sufficiently healed ligaments was found following surgical repair, although this was not reflected in the ultrasound evaluation.

\section{Keywords}

Joint dislocations - Lateral ligaments . Translation · Joint flexibility · Residual elbow instability

\section{Ellenbogenstabilität nach ligamentärer Ellenbogenluxation. Vorläufige Ergebnisse mit konservativer Therapie vs. operative Bandrekonstruktion}

\section{Zusammenfassung}

Ziel. Ziel dieser Studie ist der Vergleich der klinischen Ergebnisse von Patienten mit ligamentärer Ellenbogenluxation nach konservativer (Gruppe A) bzw. operativer Therapie mittels Bandnaht (Gruppe B). Material und Methodik. Zwischen Januar 2015 und Dezember 2018 wurden retrospektiv 30 Patienten mit rein ligamentärer Ellenbogenluxation ermittelt. Von diesen waren $n=9$ konservativ und $n=21$ operativ mit Bandnaht behandelt worden. Das Bewegungsausmaß für Extension/Flexion und Pronation/Supination sowie Hinweise für Valgusinstabilität bzw. posterolaterale Rotationsinstabilität wurden klinisch beurteilt. Verschiedene Scores zur Ergebnismessung nach Ellenbogenverletzung wurden erhoben. Sonographisch wurde bei allen Patienten die Angulation bzw. Translation des Ellenbogens unter Valgus- bzw. posterolateralem Rotationsstress bestimmt.

Ergebnisse. Nachuntersucht wurden 14 Patienten nach ligamentärer Ellenbogenluxation: Gruppe A: $n=5$, durchschnittliches (ø) Alter: 46,4 $\pm 19,3$ Jahre, $\varnothing$ Follow-up, FU: $27 \pm 12,4$ Monate; Gruppe B: $n=9, \varnothing$ Alter: $57,3 \pm 21,0$ Jahre, $\varnothing$ FU: $36 \pm 11,1$ Monate. Davon waren jeweils $n=4$ Frauen in beiden Gruppen. Das Bewegungsausmaß zeigte weder für Extension/Flexion noch den Ext/Flex-Bogen einen signifikanten Unterschied, es gab jedoch eine Tendenz zur eingeschränkten Extension $(p=0,07)$ in Gruppe A. Im Vergleich zur gesunden Gegenseite wurde eine signifikant reduzierte Supination $\left(84 \pm 15^{\circ}\right.$ vs. $77 \pm 21^{\circ}$, $p=0,02$ ) in der Gruppe B beobachtet. Die erhobenen Scores wiesen keine signifikanten Unterschiede zwischen den Gruppen auf. Bei der sonographischen Stabilitätsuntersuchung stellte sich eine signifikant vermehrte mediale Angulation im Vergleich zur Gegenseite der Gruppe B dar.

Schlussfolgerung. Diese vorläufigen Ergebnisse zeigen keine relevanten Unterschiede hinsichtlich Bewegungsausmaß und funktioneller Scores nach konservativer bzw. operativer Therapie einer ligamentären Ellenbogenluxation. Dennoch wurde bei der klinischen Untersuchung eine höhere Rate an suffizient eingeheilten Seitenbändern festgestellt, auch wenn dies in der sonographischen Untersuchung nicht nachzuvollziehen war.

Schlüsselwörter

Gelenkluxationen · Seitenbänder · Translation - Gelenkbeweglichkeit - Residuale Ellenbogeninstabilität

\section{Ultrasound evaluation}

All patients underwent standardized examinations of both elbows carried out by the same examiner. The ultrasound evaluation was performed with a multifrequency $(10-5 \mathrm{MHz})$ linear array transducer and an iViz FUJIFILM SonoSite ultrasound system (Fujifilm SonoSite, Amsterdam, The Netherlands).
All patients were placed in a supine position. The medial elbow was examined as described by Sasaki et al. [21].

The transducer was placed in a position where the medial epicondyle and the sublime tubercule of the ulna were portrayed in the ultrasonic image. The ulnohumeral joint space was defined as the non-echoic space between the medial epicondyle and the ulna. The dis- tance without valgus stress was measured in millimeters on the ultrasound device using the measurement tool of the manufacturer (- Fig. 1). Afterwards the elbow was stressed in a valgus position, as described by Kerschbaum et al., and the distance was measured [11]. The difference of both measurements was calculated.

Similar to the measurement of the valgus stress angulation, PLRI was evaluated 
Table 1 Functional scores

\begin{tabular}{|c|c|c|}
\hline $\begin{array}{l}\text { Functional } \\
\text { scores }\end{array}$ & $\begin{array}{l}\text { Group 1: nonoperative treatment } \\
\text { Point value (average } \pm \text { SD) }\end{array}$ & $\begin{array}{l}\text { Group 2: ligament repair } \\
\text { Point value (average } \pm \text { SD) }\end{array}$ \\
\hline SEV & $82 \pm 15$ & $85 \pm 12$ \\
\hline MEPS & $90 \pm 20$ & $91 \pm 11$ \\
\hline Quick DASH & $20.9 \pm 27.6$ & $9.8 \pm 12.6$ \\
\hline $\begin{array}{l}\text { Broberg and } \\
\text { Morrey }^{\mathrm{a}}\end{array}$ & $94 \pm 8.4$ & $94 \pm 9.4$ \\
\hline OES & $55.8 \pm 7.3$ & $54.7 \pm 6.1$ \\
\hline \multicolumn{3}{|c|}{$\begin{array}{l}\text { SEV Subjective Elbow Value, MEPS Mayo Elbow Performance Score, DASH Disability of the Arm } \\
\text { Shoulder and Hand, OES Oxford Elbow Score } \\
\text { 'Broberg and Morrey rating system }\end{array}$} \\
\hline
\end{tabular}

using the tip of the lateral epicondyle and the radial head as reference. Two measurements were taken: one with a valgus stress maneuver and the second following a hypersupination movement to the forearm ([11]; • Fig. 2).

\section{Statistical analysis}

All patients forming part of the study to date were included in the statistical analysis. The statistical analyses were performed using the software R (R Foundation for Statistical Computing, Vienna, Austria). The authors are aware, however, that due to the limited number of patients, statistical analysis is not meaningful.

\section{Results}

To date 14 patients with simple elbow dislocation have been evaluated. Five patients with an average age of $46.4 \pm 19.3$ years were treated nonoperatively (group A). The average follow-up was $27 \pm 12.4$ months and there were four female patients in this group. Group B (female patients, $n=4$ ) consisted of nine patients with an average age of $57.3 \pm 21.0$ years and an average followup of $36 \pm 11.1$ months.

\section{Clinical and functional results}

No significant difference was observed between the two groups in terms of ROM (extension/flexion arc and pronation/supination arc). A significant reduced supination $\left(84 \pm 15^{\circ}\right.$ vs. $77 \pm 21^{\circ}$, $p=0.02$ ) compared with the contralateral side was found in group B, although the clinical relevance is questionable.

No recurrent dislocation occurred in the two groups. Two patients in group A showed clinical signs of medial and lateral instability, whereas only one patient in group B showed clinical bilateral instability. In group $\mathrm{A}$, one patient had a positive valgus stress test result but a negative moving valgus test result and normal findings during ultrasound testing. In group B one patient had a positive posterolateral rotatory apprehension test (PRAT) result but negative signs for PLRI as well as an unremarkable ultrasound evaluation (• Table 1).

During ultrasound evaluation, a significantly increased medial angulation (average $\Delta 0.08 \mathrm{~cm}$ vs. $0.02 \mathrm{~cm} p=0.05$ ) was found compared with the contralateral side. But further parameters, especially those concerning PLRI evaluation, did not reveal relevant differences neither with the healthy contralateral side.

A significantly increased medial angulation during ultrasound evaluation was noted in group $\mathrm{B}$ when compared with the contralateral side. Further evaluated parameters of posterolateral rotatory translation and angulation did not show any relevant differences.

\section{Results of ultrasound evaluation}

The ultrasound evaluation showed significant differences in the surgically treated group regarding the valgus stress angulation when compared with the mean $0.2 \pm 0.4 \mathrm{~mm}, p<0.05)$. Similar, although non-significant, results were between the two groups nor compared non-affected side (mean $0.8 \pm 0.9 \mathrm{~mm}$ vs. obtained in the conservatively treated group (mean $1.1 \pm 1.5 \mathrm{~mm}$ vs. mean $0.6 \pm 0.9 \mathrm{~mm}$, n.s.). In both groups, no difference was seen regarding PLRI when measured by humeroradial joint width in comparison with the non-affected side (• Fig. 3).

\section{Following surgeries}

Two patients in group A had a surgical intervention. One patient had a distinctly reduced ROM and underwent arthroscopic arthrolysis approximately 9 months after dislocation. During arthroscopic evaluation of stability, a PLRI grade of 1 according to O'Driscoll et al. was detected [18]. Although an enhanced ROM was present during followup, it did not reach the magnitude of the contralateral side and persistent signs of PLRI were detected during clinical and ultrasound evaluation (posterolateral rotatory translation $\Delta 0.39 \mathrm{~cm}$ vs. $0.08 \mathrm{~cm}$ ).

The second patient was referred to our department approximately 6 weeks after dislocation and nonoperative treatment for small osteochondral fragments. These were removed arthroscopically. Stability testing during surgery revealed a posterolateral instability of grade 1 according to O'Driscoll et al. [18]. At follow-up no relevant reduction in ROM, instability, or increased translation during ultrasound evaluation was detected. The patient scored $90 \%$ in the SEV and did not have any relevant decreased functional limitations (MEPS 100P, QuickDASH 34.1).

\section{Discussion}

Nonoperative treatment as well as ligament repair following ligamentous elbow dislocation will result in good patient satisfaction and ROM as well as reproducible functional results.

However, a higher rate of clinical signs of instability was observed after nonoperative treatment, which might indicate a reduced ligament healing capacity. Nevertheless, these clinical observations were not seen at the ultrasound evaluation. In this small patient cohort, there were no significant differences detected 


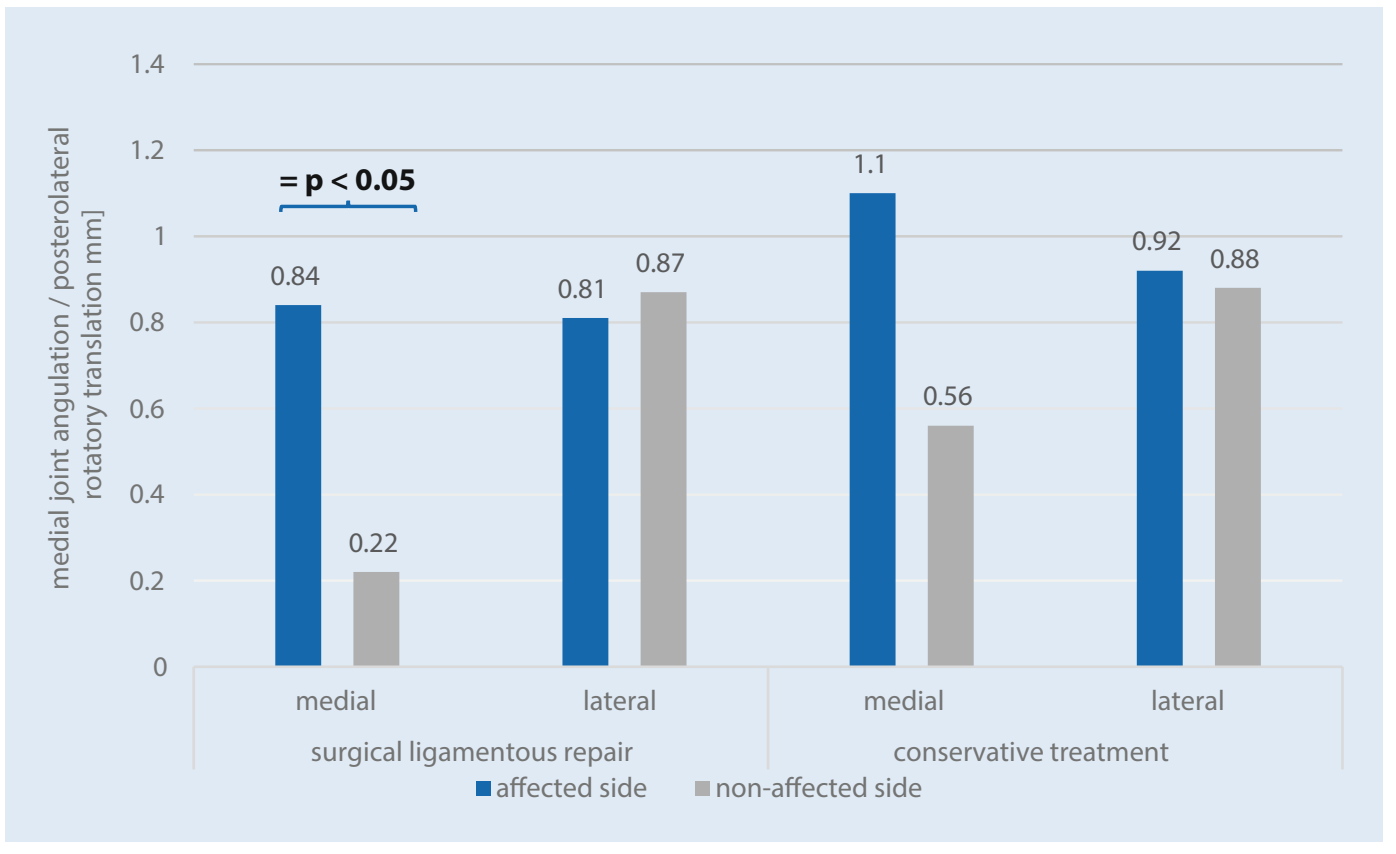

Fig. $3<$ Comparison of ultrasound-evaluated medial joint angulation and posterolateral rotatory translation in the two groups in valgus stress angulation or posterolateral rotatory translation compared with the contralateral side to support the clinical findings.

In a retrospective study, Kerschbaum et al. found an increased valgus angulation and PLRI following nonoperative treatment of ligamentous elbow instability [11]. In a small cohort of ten patients, an increased medial angulation was detected in four individuals, one of them having clinical signs of medial instability. On the lateral side, seven patients had increased posterolateral translation during sonographic evaluation and three of them showed clinical PLRI. The authors concluded that sufficient ligament healing cannot be expected following nonoperative treatment.

In a larger group of 20 patients Beirer et al. demonstrated good clinical results in patients treated nonoperatively and with ligament repair [4]. No significant differences were detected in the Elbow Self-Assessment Score or concerning ROM. The authors evaluated medial as well as lateral angulation in $0^{\circ}$ and $30^{\circ}$ of flexion and fully supinated forearm. The lateral instability of the elbow tends to manifest itself as rotational instability rather than varus angulation [18]. Thus, one might not expect to find any differences in ultrasound evaluation using a varus stress test to detect insufficient ligament healing. This is why we decided to use rotatory stress (hypersupination) to evaluate for posterolateral translation, as evaluated by Kerschbaum et al. [11]. Still, similar to our results, the ultrasound parameters evaluated by Beirer et al. revealed a wide range and were not assigned to clinical symptoms [4]. Different causes could be responsible for the varying results with wide-spreading values. First, musculoskeletal sonography is highly operator-dependent, and thus the variety and inaccuracy due to probe placement should not be underestimated.

Furthermore, like many other joints, the elbow can be stabilized by muscle contracture, and therefore it might be difficult or impossible to detect any translation or angulation of the elbow if there is muscular tension. Muscular tension can be caused by an uncomfortable position or situation, as well as pain or a feeling of instability. Furthermore, it is quite difficult to achieve a constant positioning of the transducer at the epicondyles during stress application. Minimal rotation or slippage will lead to inaccurate results. Nevertheless, a moderateto-excellent reliability and a high interclass correlation coefficient was shown in evaluating the ulnohumeral joint gapping and ulnar collateral ligament length by Bica et al. [5]. The authors evaluated healthy athletes without signs of instability and no prior surgery around the elbow. Following dislocation of the elbow and particularly after ligament repair, the sonographic presentation of the ligaments and bony references are distorted. This will make it more difficult to achieve a reliable ultrasound measurement.

Concerning the diagnosis and objectification of PLRI using ultrasound evaluation, a potentially decreased reliability can be assumed because of the rotational component of the instability compared with the angulation instability at the medial side of the elbow. To work around this problem, Camp et al. converted the rotation to an angulation measurement using ulnohumeral widening to quantify PLRI [6]. Doing so, the probe is placed in an anatomical axis plane at the posteroradial aspect of the elbow between the lateral epicondyle and olecranon. After applying posterolateral stress, the change in ulnohumeral distance can be measured.

Nevertheless, these emerging ultrasound techniques still need further validation to determine their value in detecting and measuring elbow instability [7].

\section{Limitations}

The most notable limitation of this study is the small sample size, the low follow-up 
rate and the associated increase in standard deviation that was observed in other studies as well $[4,5,11]$. Furthermore, because of the retrospective design of this study, the assignment to the groups was not randomized. The indication for ligament repair was based on the severity of the injury and ability for muscular compensation of the instability allowing for a stable arc of motion up to approximately $30^{\circ}$ of extension. Potentially, it can be assumed that patients with a lower injury severity were treated more conservatively. It is obvious that this leads to a selection bias and a statement as to whether one form of therapy is superior to the other is not possible. Still, this would mainly affect the clinical results and to a lesser extent the radiological values.

\section{Practical conclusion}

\section{- The preliminary results of these in- homogeneous groups showed that there were no significant differences concerning range of motion and func- tional scores between nonoperative treatment and surgical ligamentous repair. \\ - Nevertheless, during clinical eval- uation, a higher rate of sufficiently healed ligaments was found fol- lowing surgical repair although this was not reflected in the ultrasound evaluation.}

\section{Corresponding address}

\section{Dr. Christian Gerhardt}

Klinik für Unfall- und Handchirurgie, ViDia Kliniken Karlsruhe

Südendstraße 32, 76137 Karlsruhe, Germany christian.gerhardt@vincentius-ka.de

\section{Compliance with ethical guidelines}

Conflict of interest. J. Willin, J. Schmalzl, L. Lehmann, and C. Gerhardt declare that they have no competing interests.

The study was approved by the local ethic committee. All patients gave their written informed consent before being included in the study.

Open Access. This article is licensed under a Creative Commons Attribution 4.0 International License, which permits use, sharing, adaptation, distribution and re- production in any medium or format, as long as you give appropriate credit to the original author(s) and the source, provide a link to the Creative Commons licence, and indicate if changes were made. The images or other third party material in this article are included in the article's Creative Commons licence, unless indicated otherwise in a credit line to the material. If material is not included in the article's Creative Commons licence and your intended use is not permitted by statutory regulation or exceeds the permitted use, you will need to obtain permission directly from the copyright holder. To view a copy of this licence, visit http://creativecommons.org/licenses/by/4.0/.

\section{References}

1. Adolfsson LE, Nestorson JO, Scheer JH (2017) Extensive soft tissue lesions in redislocated after simple elbow dislocations. J Shoulder Elbow Surg 26:1294-1297. https://doi.org/10.1016/j.jse.2017. 02.019

2. Anakwe RE, Middleton SD, Jenkins PJ, MCQueen MM, Court-Brown CM (2011) Patientreported outcomes after simple dislocation of the elbow. J Bone Joint Surg Am 93:1220-1226. https://doi.org/10.2106/JBJS.J.00860

3. Arvind CHV, Hargreaves DG (2006) Tabletop relocation test: a new clinical test for posterolateral rotatory instability of the elbow. J Shoulder Elbow Surg 15:707-708. https://doi.org/10.1016/j.jse. 2006.01.005

4. Beirer $M$, Willinger $L$, Laccheta $L$, Buchholz $A$, Lenich A, Imhoff AB, Siebenlist S (2018) Subjektives und funktionelles Outcome nach akutligamentärer Ellenbogenluxation. Obere Extremität 13:197-203. https://doi.org/10.1007/s11678018-0468-y

5. Bica D, Armen J, Kulas AS, Youngs K, Womack Z (2015) Reliability and precision of stress sonography of the ulnar collateral ligament. J Ultrasound Med 34:371-376. https://doi.org/10.7863/ultra. 34.3.371

6. Camp CL, O'Driscoll SW, Wempe MK, Smith J (2017) The sonographic posterolateral rotatory stress test for elbow instability: a cadaveric validation study. PM R 9:275-282. https://doi.org/10.1016/j.pmrj. 2016.06.014

7. Camp CL, Smith J, O'Driscoll SW (2017) Posterolateral rotatory instability of the elbow: part II. Supplementary examination and dynamic imaging techniques. Arthrosc Tech 6:e407-e411. https://doi.org/10.1016/j.eats.2016.10.012

8. Eygendaal D, Verdegaal SH, Obermann WR, van Vugt AB, Pöll RG, Rozing PM (2000) Posterolateral dislocation of the elbow joint. Relationship to medial instability. J Bone Joint Surg Am 82:555-560

9. lordens GIT, Van Lieshout EMM, Schep NWL, De Haan J, Tuinebreijer WE, Eygendaal D, Van Beeck E, Patka P, Verhofstad MHJ, Den Hartog D (2017) Early mobilisation versus plaster immobilisation of simple elbow dislocations: results of the FuncSiE multicentre randomised clinical trial. $\mathrm{Br} \mathrm{J}$ Sports Med 51:531-538. https://doi.org/10.1136/ bjsports-2015-094704

10. Josefsson PO, Gentz CF, Johnell O, Wendeberg B (1987) Surgical versus non-surgical treatment of ligamentous injuries following dislocation of the elbow joint. A prospective randomized study. JBone Joint Surg Am 69:605-608

11. Kerschbaum M, Thiele K, Scheibel M, Gerhardt C (2016) Residual increased valgus stress angulation and posterolateral rotatory translation after simple elbow dislocation. Knee Surg Sports Traumato Arthrosc 25:2298-2303. https://doi.org/10.1007/ s00167-016-4176-0

12. Luokkala T, Temperley D, Basu S, Karjalainen TV, Watts AC (2019) Analysis of magnetic resonance imaging-confirmed soft tissue injury pattern in simple elbow dislocations. J Shoulder Elbow Surg 28:341-348. https://doi.org/10.1016/j.jse.2018. 08.010

13. Maripuri SN, Debnath UK, Rao P, Mohanty K (2007) Simple elbow dislocation among adults: a comparative study of two different methods of treatment. Injury 38:1254-1258. https://doi.org/ 10.1016/j.injury.2007.02.040

14. Mayne IP, Wasserstein D, Modi CS, Henry PDG, Mahomed N, Veillette C (2015) The epidemiology of closed reduction for simple elbow dislocations and the incidence of early subsequent open reduction. J Shoulder Elbow Surg 24:83-90. https://doi.org/10.1016/j.jse.2014.08.027

15. Modi CS, Wasserstein D, Mayne IP, Henry PDG, Mahomed N, Veillette CJH (2015) The frequency and risk factors for subsequent surgery after a simple elbow dislocation. Injury 46:1156-1160. https://doi.org/10.1016/j.injury.2015.02.009

16. O'Driscoll SW (2000) Classification and evaluation of recurrent instability of the elbow. Clin Orthop Relat Res 370:34-43. https://doi.org/10.1097/ 00003086-200001000-00005

17. O'Driscoll SW, Jupiter JB, King GJW, Hotchkiss RN, Morrey BF (2000) The unstable elbow. JBone Joint Surg Am 82:724

18. O'Driscoll SW, Morrey BF, Korinek S, An KN (1992) Elbow subluxation and dislocation. A spectrum of instability. Clin Orthop Relat Res 280:186-197

19. O'Driscoll SWM, Lawton RL, Smith AM (2005) The "moving valgus stress test" for medial collateral ligament tears of the elbow. Am J Sports Med 33:231-239. https://doi.org/10.1177/ 0363546504267804

20. Regan W, Lapner PC (2006) Prospective evaluation of two diagnostic apprehension signs for posterolateral instability of the elbow. J Shoulder Elbow Surg 15:344-346. https://doi.org/10.1016/j.jse. 2005.03.009

21. Sasaki J, Takahara M, Ogino T, Kashiwa H, Ishigaki D, Kanauchi Y (2002) Ultrasonographic assessment of the ulnar collateral ligament and medial elbow laxity in college baseball players. J Bone Joint Surg Am 84:525-531. https://doi.org/10.2106/ 00004623-200204000-00003

22. Schnetzke $M$, Aytac $S$, Studier-Fischer $S$, Grützner P-A, Guehring T (2015) Initial joint stability affects the outcome after conservative treatment of simple elbow dislocations: a retrospective study. J Orthop Surg Res 10:155-159. https://doi.org/10.1186/s13018-015-0273-x

23. Schwab GH, Bennett JB, Woods GW, Tullos HS (1980) Biomechanics of elbow instability: the role of the medial collateral ligament. Clin Orthop Relat Res 146:42-52

24. Stoneback JW, Owens BD, Sykes J, Athwal GS, Pointer L, Wolf JM (2012) Incidence of elbow dislocations in the United States population. JBone Joint Surg Am 94:240-245. https://doi.org/ 10.2106/JBJS.J.01663

25. Szekeres M, Chinchalkar SJ, King GJW (2008) Optimizing elbow rehabilitation after instability. Hand Clin 24:27-38. https://doi.org/10.1016/j.hcl. 2007.11.005

26. Thiele K, Scheibel M (2018) Diagnosis of elbow instability and algorithm for treatment. Obere Extremität 13:160-172. https://doi.org/10.1007/ s11678-018-0480-2 